\title{
Subsidized pharmacological treatment for smoking cessation by the Spanish public health system: A randomized, pragmatic, clinical trial by clusters
}

\author{
César Minué-Lorenzo ${ }^{1}$,Eduardo Olano-Espinosa ${ }^{2,3}$, Isabel del Cura-Gonzálezz,4,5, Jose M. Vizcaíno-Sánchez ${ }^{6}$, Francisco \\ Camarelles-Guillem7, José A. Granados-Garrido ${ }^{8}$, Margarita Ruiz-Pacheco ${ }^{9}$, M. Isabel Gámez-Cabero ${ }^{10}$, F. Javier \\ Martínez-Suberviola ${ }^{8}$ Encarnación Serrano-Serrano ${ }^{11}$
}

\begin{abstract}
INTRODUCTION Research has shown that financing drug therapy increases smoking abstinence rates, although most of these studies have been carried out in the private healthcare setting. The aim of this work is to assess the effect of subsidized pharmacological treatment on smoking cessation rates by the Spanish public healthcare system.

METHODS A pragmatic, randomized, clinical trial was performed by clusters. Randomization unit was the primary healthcare center and the analysis unit was the patient. Smokers consuming $\geq 10$ cigarettes/day were randomly assigned to an intervention group that received financed pharmacological treatment or to a control group that followed usual care. The main outcome was self-reported or CO-confirmed continuous abstinence at 12 months. The main outcome, continuous abstinence rates (\%), were compared between groups at 12 months post-intervention. A model was adjusted using mixedeffect logistic regression.

RESULTS A total of 1154 patients were included from 23 healthcare centers. In the intention-to-treat analysis, selfreported abstinence after 12 months in the control and intervention groups, respectively, was $9.6 \%(37 / 387)$ and $15.4 \%(118 / 767)$ (gender-adjusted OR=1.75; 95\% CI: $1.1-$ 2.8); for CO-confirmed abstinence the corresponding values were $3.1 \%(12 / 387)$ and $6.4 \%(49 / 767)$ (gender-adjusted $\mathrm{OR}=1.72$; 95\% CI: 0.7-4.0). Pharmacological treatment use was $35.1 \%(136 / 387)$ in the control group, and 58.3\% (447/767) in the intervention group (adjusted OR=4.25; 95\% CI: $1.8-9.9$ ) CONCLUSIONS Subsidizing pharmacological treatment for smoking cessation increases self-reported or CO-confirmed abstinence rates under realistic conditions in the primary care setting of the Spanish public health system.
\end{abstract}

\author{
AFFILIATION \\ 1 Perales del Río Health Center, Dirección Asistencial \\ Centro, Servicio Madrileño de Salud, Madrid, Spain \\ 2 Los Castillos Health Center, Dirección Asistencial \\ Oeste, Servicio Madrileño de Salud, Madrid, Spain \\ 3 Area Medicina Preventiva y Salud Pública, \\ Universidad Rey Juan Carlos, Madrid, Spain \\ 4 Unidad de Apoyo a la Investigación, Gerencia \\ Asistencial de Atención Primaria, Servicio Madrileño de \\ Salud, Madrid, Spain \\ 5 Red de Investigación Servicios de Salud en \\ enfermedades crónicas, REDISSEC, Madrid, Spain \\ 6 Fuentelarreina Health Center, Dirección Asistencial \\ Norte, Servicio Madrileño de Salud, Madrid, Spain \\ 7 Infanta Mercedes Health Center, Dirección Asistencial \\ Norte, Servicio Madrileño de Salud, Madrid, Spain \\ 8 Guayaba Health Center, Dirección Asistencial Centro, \\ Servicio Madrileño de Salud, Madrid, Spain \\ 9 Doctor Castroviejo Health Center, Dirección \\ Asistencial Norte, Servicio Madrileño de Salud, Madrid, \\ Spain \\ 10 Majadahonda Valle de la Oliva Health Center, \\ Dirección Asistencial Noroeste, Servicio Madrileño de \\ Salud, Madrid, Spain \\ 11 Los Fresnos Health Center, Dirección Asistencial Este, \\ Servicio Madrileño de Salud, Madrid, Spain
}

\section{CORRESPONDENCE TO}

César Minué-Lorenzo. Perales del Río Health Center, Dirección Asistencial Centro, Servicio Madrileño de Salud, Juan de Mairena s/n. 28909 Getafe, Madrid, Spain. E-mail: cesaraugusto.minue@salud.madrid.org ORCID ID: https://orcid.org/0000-0002-8015-3378

\section{KEYWORDS}

smoking cessation, drug therapy, primary health care, healthcare financing, Spain

\section{Received: 27 April 2019}

Revised: 4 July 2019

Accepted: 27 July 2019

\section{INTRODUCTION}

An array of interventions have been shown to be both efficacious and cost-effective in helping patients quit smoking ${ }^{1}$. Among these are pharmacological 
treatments, which show a greater than twofold increase in the rate of successful cessation ${ }^{1,2}$.

Clinical practice guidelines recommend adding drug therapy to behavioral treatment of smokers attempting to quit, with some exceptions ${ }^{1}$. However, in the primary care setting, these types of interventions are uncommon, non-standardized ${ }^{3-5}$, and rarely include pharmacological treatment ${ }^{5-7}$. The treatment cost and lack of financing by the public healthcare system may be one of the reasons for not being more widely used ${ }^{8}$.

The Cochrane Systematic Reviews ${ }^{9}$ have assessed the effectiveness of funding treatments for smoking cessation and concluded that full financing of the treatment increases abstinence rates and number of attempts, almost doubling the rate of use of nicotine replacement therapy (NRT) and tripling that of Bupropion. Studies that compared the effect of funding the cessation obtained a combined relative risk for abstinence for at least 6 months of 1.77 (95\% CI: $1.37-2.28)$ and 1.27 (95\% CI: 1.02-1.59) in the case of full and partial funding, respectively.

A study has been published, using ecological momentary assessment methods with an interrupted time-lapse analysis, of fully financed smoking cessation treatments during 2011 by the Netherlands government, including drug therapy. In the studied period, primary care doctors prescribed more therapeutic drugs and smoking prevalence decreased. However, once the pharmacological coverage ceased, drug prescriptions decreased and smoking prevalence rebounded ${ }^{10}$. The number of smokers attended to by the Dutch telephone help-line for smoking cessation went from 848 in 2010 to 9091 in 2011 and dropped drastically after the funding ended in 2012 (only 151 in the first 18 weeks) $)^{11}$.

Pharmacological treatment is considered a complementary measure to others that decrease smoking addiction prevalence ${ }^{11,12}$ such as increasing tobacco taxes or smoke-free areas ${ }^{13}$. It is especially relevant for highly-dependent and low-income smokers, who show greater difficulties to quit smoking ${ }^{14-16}$, and has been associated with a decrease in hospital admissions due to cardiovascular disease ${ }^{17}$.

Most relevant studies have been conducted in the private healthcare setting, mainly in the USA ${ }^{9}$. In the public healthcare setting, two main studies have been performed, a pilot study with short-term outcomes in the United Kingdom primary care system ${ }^{18}$, whose National Health System is similar to the Spanish one, and a subsequent study in the Canadian Health System, which is public with private provision ${ }^{19}$. Primary care in Spain is organized in healthcare centers (HCCs), with public provision, where both health and non-health professionals work together to attend to users in their health area. Care for smokers, which is included in the services provided by health professionals as paid work, encompasses counselling, behavioral interventions, and suggesting pharmacological treatment at the patient's expense. The aim of this study was to know whether funding pharmacological treatment for smoking cessation in primary care increases abstinence rates under realistic conditions.

\section{METHODS}

A pragmatic, controlled, clinical trial was performed with paralleled groups randomized by clusters. The trial was approved by the Ethics Committee for Clinical Research of Hospital Doce de Octubre de Madrid.

Ninety-six HCGs in the Health System of the Community of Madrid were asked to participate. The HCCs were selected by convenience among those interested in participating. The inclusion criterion for HCGs was: having at least one doctor interested in participating in the trial. Twenty-nine HCCs, which provide health care to a population of 925000 citizens, aged $>14$ years, accepted to participate.

The inclusion criteria for the patients were: aged $>18$ years who attended the healthcare center for any reason between June and December 2009, smoking $\geq 10$ cigarettes/day, at any stage of the smoking cessation process, attended by a general practitioner or nurse that addressed smoking cessation following usual clinical practice, and a signed informed consent. Pregnant and nursing women were excluded ${ }^{1}$.

\section{Sample size and sampling}

Sample size was calculated considering that $8 \%$ of smokers treated with the intervention would stay abstinent after 1 year $^{20}$, a clinical significance of $75 \%$ improvement post-intervention, a type I error of $5 \%$, and a power of $80 \%$. The obtained sample size was 459 patients. After controlling for the design effect, estimating an average cluster size of 25 patients and 
intraclass correlation coefficient of 0.02 , and adding $20 \%$ of losses to follow-up, a total of 1632 smokers were included, with 816 per group. Allocation was performed by clusters, the primary HCC being the randomization unit. The 29 HCCs were assigned to the intervention or the control group following a simple, computer-generated random sequence (EPIDAT 3.1 software). Randomization was performed centrally by a researcher not involved in the study, and who was blind to the identity of the HCGs.

\section{Intervention}

Behavioral treatment and recommendation for using pharmacological treatment were administered to both groups, in accordance with standard health services offered in primary care. In order to homogenize criteria and guarantee quality care for the smoker, general practitioners and nurses from the included healthcare centers received specific training as proposed by Olano et al. ${ }^{21}$.

Patients in the intervention group received firstline pharmacological treatment free-of-charge. The active ingredient (nicotine, Varenicline, or Bupropion) was chosen by the health professional in accordance with the patient's preferences. Treatment doses were standard: NRT according to the number of cigarettes smoked, Bupropion at 150-300 mg/d and Varenicline at $1-2 \mathrm{mg} / \mathrm{d}$. Treatment combinations were allowed at the discretion of the physician, such as NRT patch-plus or Bupropion and nicotine gum. The proposed standard duration was 8 weeks for NRT and Bupropion, and 12 weeks for Varenicline. Medication was distributed to the participating HCCs from the pharmacy services of the public health system. In the first visit, patients were given treatment for 2 weeks. At subsequent visits, they were given treatment for 1 month.

Patients in the control group were prescribed the treatment at the consultation and had to purchase it.

As it was a pragmatic trial, no visits other than standard practice were offered. Follow-up visits were left to the discretion of the professionals, according to their usual practice. The patients were followed for 12 months from the quit date, until December 2010.

Patients who did not intend to quit smoking were offered advice, but they were not given an appointment in either group.

\section{Variables}

Main outcome variables were: continuous abstinence according to the criterion by Russe $\mathrm{l}^{22}$ and biochemically validated abstinence through CO-oximetry. Appointments were given to patients that confirmed abstinence for validation via a CO-oximetry test, by Smokerlyzer Pico cooximeter, with a cut-off point of $<7 \mathrm{ppm}$.

Secondary outcome variables were: use of pharmacological treatment and type of therapeutic drug (nicotine, Bupropion, and Varenicline). Data were collected at 12 months \pm 4 weeks from the quit date from electronic clinical records or, when information was not available, abstinence was confirmed via telephone call.

Baseline variables were: age, gender, educational level, socioeconomic level, daily cigarette consumption, pack-years, score in the Fagerström Test for Nicotine Dependence (FTND), previous attempts to quit, stage of change, and previous use of drug therapy.

\section{Statistical analysis}

A descriptive analysis, of frequencies for qualitative variables and mean with standard deviation (SD) for quantitative variables, was performed. The groups were compared at the baseline in terms of outcome variables, descriptive variables, and prognosis factors. A bivariate analysis to compare variables was performed, using a chi-squared test and a Student's t-test, in the case of dichotomous and continuous variables, respectively.

Main outcome was percentages of self-reported or CO-oximetry validated abstinence compared between the intervention and control groups, with 95\% confidence intervals (95\% CI). Intention-to-treat data analysis was performed at 12 months. Missing values for the main outcome variable were added using the 'basal observation carried forward' method. For the secondary aim analysis, effectiveness was evaluated by comparing the differences in the percentages of pharmacological treatment use at 12 months between both groups, and corresponding 95\% CI.

A multilevel, logistic regression model was built at 12 months, where the dependent variable was self-reported (Yes/No) or CO-oximetry validated abstinence (Yes/No) or pharmacological treatment use (Yes/No), respectively, and the independent variable was the patient's allocation group. Clinically 
significant variables were also tested as covariates, taking into consideration sampling by clusters.

Statistical SPSS 21 and STATA 14 software were employed for all calculations.

\section{RESULTS}

A total of 255 health professionals from 23 healthcare centers participated in the trial and 1154 patients were included, 387 in the control group and 767 in the intervention group. Figure 1 shows the flow chart of participants throughout the trial. No differences were found in terms of number of consultations, rural or urban setting, and sociocultural level between the 6 non-participating centers ( 5 in the control arm and 1 in the intervention arm) and those participating in the study.

Baseline data were similar for both groups except that the intervention group comprised a larger percentage of men, smoked more cigarettes per day, and showed higher scores in the FTND (Table 1). Additionally, the rate of patients at the preparation and action stages of the cessation process was significantly higher in the intervention group.

Losses to follow-up were similar in both groups, with values of $7 \%(n=54)$ and $8.5 \%(n=32)$ in the intervention and control groups, respectively $(p=0.38)$. Compared to the intervention group, subjects lost to follow-up in the control group had a higher income level ( $70 \%$ vs $30 \%, p=0.045)$ and used less drugs ( $15 \%$ vs $85 \%, p=0.007)$.

With regard to the main outcome, the patients who self-reported having quit smoking at the 12 months follow-up were $118(15.4 \%)$ and $37(9.6 \%)$ in the intervention and control groups, respectively. Of these, 57 (48\%) from the intervention group and $14(38 \%)$ from the control group attended the COoximetry validation appointment, and abstinence was confirmed in the case of 49 patients $(6.4 \%)$ from the funded-treatment group and $12(3.1 \%)$ from the non-funded (Table 2). Abstinence rates were higher for subjects with higher income level for both arms (Table 3). The difference in abstinence rates and use of pharmacological treatment between high-income (>€26000/year) and low-income subjects (<€26000/ year) was reduced after financing of the treatment (Table 3). Having used therapeutic drugs in previous attempts increased the success of quitting in the financed-treatment group (Table 4).

For the secondary outcome use of pharmacological treatment was significantly greater in the case of the subsidized arm (58.3\%) compared to the nonfinanced (35.1\%) (Table 2).

Four per cent of the abstinence variability per year is explained by clusters (HCCs). The MOR (median odds ratio) between centers was 1.4, which can be interpreted as the increase in risk (median) that an individual would have if they were moved from one center to another with a higher risk.

\section{Figure 1. Flow chart of participants}

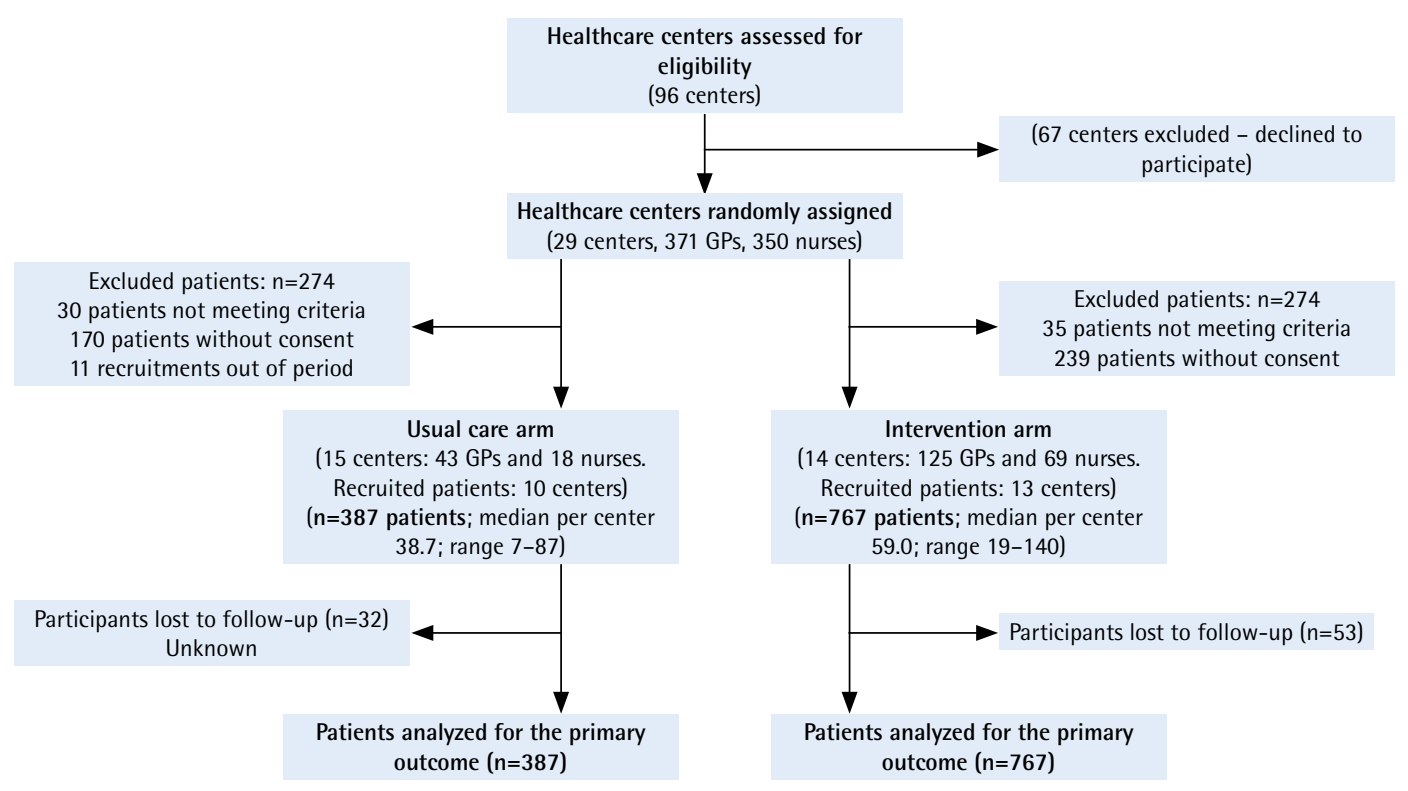


Table 1. Baseline characteristics of participants by group

\begin{tabular}{|c|c|c|c|c|}
\hline Characteristics & $\begin{array}{c}\text { Total } \\
n-1151\end{array}$ & $\begin{array}{c}\text { Control group } \\
\text { n } 387\end{array}$ & $\begin{array}{l}\text { Intervention group } \\
\qquad 11767\end{array}$ & $p$ \\
\hline Age (years), mean (SD) & $46.04(11.78)$ & $46.6(12.06)$ & $45.8(11.64)$ & 0.268 \\
\hline \multicolumn{5}{|l|}{ Gender, n (\%) } \\
\hline Male & $593(51.4)$ & $174(45.0)$ & $419(54.7)$ & 0.001 \\
\hline Female & $560(48.6)$ & $213(55.0)$ & $347(45.3)$ & \\
\hline \multicolumn{5}{|l|}{ Educational level, n (\%) } \\
\hline No studies & $25(2.5)$ & $4(1.4)$ & $20(2.9)$ & 0.184 \\
\hline Primary education & $326(32.9)$ & $102(34.7)$ & $223(32.4)$ & \\
\hline Secondary education & $387(39.0)$ & $105(35.7)$ & $279(40.5)$ & \\
\hline University & $254(25.6)$ & $83(28.2)$ & $167(24.2)$ & \\
\hline \multicolumn{5}{|l|}{ Annual income level, n (\%) } \\
\hline$<€ 26000$ & $669(69.7)$ & $191(65.6)$ & $478(71.4)$ & 0.072 \\
\hline$\geq € 26000$ & $291(30.3)$ & $100(34.4)$ & $191(28.6)$ & \\
\hline Cigarettes/day, mean (SD) & $22.0(9.5)$ & $20.6(8.6)$ & $22.6(9.9)$ & 0.012 \\
\hline Years smoking, mean (SD) & $26.5(11.9)$ & $27.1(12.4)$ & $26.1(11.6)$ & 0.190 \\
\hline Pack-years, mean (SD) & $29.6(19.9)$ & $28.6(18.7)$ & $30.2(20.5)$ & 0.220 \\
\hline Number of previous attempts, mean (SD) & $2.3(3.1)$ & $2.2(2.5)$ & $2.4(3.5)$ & 0.159 \\
\hline FTND, mean $(S D)^{*}$ & $5.4(2.2)$ & $5.2(2.1)$ & $5.5(2.3)$ & 0.035 \\
\hline Previous drug therapy, $\mathrm{n}(\%)$ & $178(25.5)$ & $68(26.6)$ & $110(24.9)$ & 0.625 \\
\hline \multicolumn{5}{|l|}{ Stage of change, $n(\%)$} \\
\hline Pre-contemplation & $252(22.2)$ & $103(26.6)$ & $150(19.6)$ & $<0.01$ \\
\hline Contemplation & $239(21.1)$ & $105(27.1)$ & $134(17.5)$ & $<0.01$ \\
\hline Preparation & $385(34.0)$ & $113(29.2)$ & $272(35.5)$ & 0.03 \\
\hline Action & $253(22.3)$ & $58(15.0)$ & $196(25.5)$ & $<0.01$ \\
\hline
\end{tabular}

${ }^{*}$ FTND: Fagerström test for Nicotine Dependence.

Table 2. Outcomes of continuous abstinence (self-reported or $\mathrm{CO}$-validated) and use of pharmacological treatment, from mixed-effect logistic regression analysis

\begin{tabular}{|c|c|c|c|c|c|c|c|}
\hline \multirow[t]{2}{*}{ Intention to treat } & \multirow{2}{*}{$\begin{array}{l}\text { Control } \\
\text { group } \\
\left.\text { n ( }{ }^{\circ} \%\right)\end{array}$} & \multirow{2}{*}{$\begin{array}{c}\text { Intervention } \\
\text { group } \\
\text { n }(\%)\end{array}$} & \multicolumn{5}{|c|}{ Rate difference } \\
\hline & & & OR $(95 \% \mathrm{CI})$ & OR raw $\left(95^{\circ} \% \mathrm{CI}\right)^{\mathrm{a}}$ & p & $A O R^{b}\left(95^{\circ} \% C I\right)$ & $p$ \\
\hline Self-reported continuous abstinence & $37(9.6)$ & $118(15.4)$ & $5.8(1.9-9.7)$ & $1.84(1.1-3.0)$ & 0.01 & $1.75(1.1-2.8)$ & 0.02 \\
\hline CO-validated continuous abstinence & $12(3.1)$ & $49(6.4)$ & $3.3(0.8-5.7)$ & $1.77(0.8-4.1)$ & 0.17 & $1.72(0.7-4.0)$ & 0.20 \\
\hline Pharmacological treatment use & $136(35.1)^{\mathrm{c}}$ & $447(58.3)^{d}$ & $23.1(17.2-29.0)$ & $4.52(2.0-10.0)$ & 0.00 & $4.25(1.8-9.9)$ & 0.00 \\
\hline NRT & $46(11.9)$ & $131(17.1)$ & $5.2(1.0-9.4)$ & $1.80(1.0-3.3)$ & 0.05 & $1.77(1.0-3.2)$ & 0.06 \\
\hline Bupropion & 45 (11.6) & $135(17.6)$ & $6.0(1.8-10.2)$ & $1.58(0.8-3.1)$ & 0.19 & $1.49(0.7-3.0)$ & 0.83 \\
\hline Varenicline & $49(12.7)$ & $199(25.9)$ & $13.2(8.7-17.8)$ & $3.40(1.8-6.4)$ & 0.00 & $3.41(1.8-6.5)$ & 0.00 \\
\hline
\end{tabular}

a Mixed-effect logistic regression, b AOR: adjusted odds ratio by gender, c 4 participants used Bupropion+NRT, d 10 used Bupropion+NRT; 7 Varenicline+NRT; 1

Bupropion+Varenicline.

All variables that showed basal differences and those that could impact the outcome from a clinical point of view were included in the multilevel model. After removing all non-significant variables, gender remained as the only adjustment factor. Selfreported continuous abstinence, adjusted by gender, was significantly greater in the intervention group $(\mathrm{OR}=1.75 ; 95 \%$ CI: 1.1-2.8); validated abstinence by $\mathrm{CO}$-oximetry was also higher $(\mathrm{OR}=1.72 ; 95 \% \mathrm{CI}$ : 0.74-4.0). Abstinence rates in both the intervention and control arms increased using NRT (OR=2.0; 95\% CI: $1.3-3.0)$, Bupropion (OR=2.3; 95\% CI: 1.5-3.4), 
Table 3. Outcomes of abstinence rates and use of pharmacological treatment by annual income level

\begin{tabular}{|c|c|c|c|c|c|}
\hline \multirow[t]{2}{*}{ Group } & & \multicolumn{2}{|c|}{ Abstinence } & \multicolumn{2}{|c|}{ Pharmacological treatment use } \\
\hline & & $\%(\mathrm{~m})$ & OR $\left(95^{\circ} \% \mathrm{CI}\right)$ & $\%(n)$ & OR $\left(95^{\circ} \% \mathrm{CI}\right)$ \\
\hline \multirow[t]{2}{*}{ Control group } & $<€ 26000$ & $7.9(15)$ & & $29.3(56)$ & \\
\hline & $\geq € 26000$ & $15.0(15)$ & $1.81(1.0-3.3)$ & $47.0(47)$ & $2.9(2.0-4.2)$ \\
\hline \multirow[t]{2}{*}{ Intervention group } & $<€ 26000$ & $13.4(64)$ & & $54.8(262)$ & \\
\hline & $\geq € 26000$ & $19.4(37)$ & $1.4(0.7-2.6)$ & 62.3 (119) & $1.9(1.1-3.0)$ \\
\hline \multirow[t]{2}{*}{ Total } & Usual practice & $10.3(30)$ & & 35.4 (103) & \\
\hline & Financed treatment & 15.1 (101) & $1.5(1.0-2.4)$ & $57.0(381)$ & $2.4(1.8-3.2)$ \\
\hline
\end{tabular}

Table 4. Outcomes of abstinence rates and use of pharmacological treatment by previous use of pharmacological treatment

\begin{tabular}{|c|c|c|c|c|c|}
\hline \multirow[t]{2}{*}{ Group } & & \multicolumn{2}{|c|}{ Abstinence } & \multicolumn{2}{|c|}{ Pharmacological treatment use } \\
\hline & & $\%(n)$ & OR $\left(95^{\circ} \circ \mathrm{CI}\right)$ & $\%(n)$ & OR $\left(95^{\circ} \% \mathrm{Cl}\right)$ \\
\hline \multirow[t]{2}{*}{ Usual practice } & No previous use of drugs & $13.3(25)$ & & $40.4(76)$ & \\
\hline & Previous use of drugs & $10.3(7)$ & $1.2(0.7-1.9)$ & $51.5(35)$ & $2.3(1.6-3.3)$ \\
\hline \multirow[t]{2}{*}{ Financed treatment } & No previous use of drugs & $15.1(50)$ & & $60.5(201)$ & \\
\hline & Previous use of drugs & $21.8(24)$ & $2.4(1.0-6.0)$ & $80.0(88)$ & $3.8(1.9-7.3)$ \\
\hline \multirow[t]{2}{*}{ Total } & Financed treatment & $16.7(74)$ & & 65.4 (289) & \\
\hline & Non-financed treatment & $12.5(32)$ & $1.4(0.9-2.2)$ & 43.4 (111) & $2.5(1.8-3.4)$ \\
\hline
\end{tabular}

Table 5. Outcomes of continuous abstinence (self-reported) with NRT, Bupropion and Varenicline

\begin{tabular}{l|c|c|c|c|c|c|}
\hline Intention to treat & VRT use & Vo VRT & Bupropion use & Vo Bupropion & Varenicline use & Vo Varenicline \\
& $n(\%)$ & $n(\%)$ & $n(\%)$ & $n(\%)$ & $n(\%)$ & n $(\%)$ \\
\hline Continuous abstinence & $38(21.5)$ & $117(12)$ & $42(23.3)$ & $113(11.6)$ & $63(25.4)$ & $92(10.2)$ \\
OR $(95 \% \mathrm{Cl})$ & $2.0(1.3-3.0)$ & & $2.3(1.6-3.4)$ & & $3.0(2.1-4.3)$ &
\end{tabular}

and Varenicline (OR=3.0; 95\% CI: 2.1-4.3) (Table $5)$. In the case of NRT, the impact was significantly greater in men $(2.75 ; 95 \%$ CI: $1.6-4.6)$ than in women (1.2; 95\% CI: 0.6-2.4).

Success in quitting smoking was greater for men $(\mathrm{OR}=1.5 ; 95 \% \mathrm{CI}: 1.1-2.2)$ and subjects with highincome level (OR=1.6; 95\% CI: 1.1-2.3).

\section{DISCUSSION}

Financing pharmacological treatment for smoking cessation in this trial significantly increased selfreported abstinence rates at the 12 months followup, and validated abstinence by $\mathrm{CO}$-oximetry. The use of drug therapy also increased significantly, especially with nicotine and Varenicline. Additionally, the number of patients willing to attempt cessation in the intervention arm was much higher (Table 1).

A design by clusters was chosen considering the organization of the Spanish healthcare system and high risk of cross-contamination between participants. The trial was conducted in real-world conditions within the public health system context, with a high number of daily consultations, which forced patient recruitment to take place after randomizing the centers. Baseline differences shown in Table 1 appear to already indicate an intervention impact prior to its initiation. At the initial visit, patients were aware of the possibility of financing the treatment, which probably encouraged many participants to escape the first stages of the process and directly proceed to attempt to quit.

After refining the multilevel model, where gender remained as the only adjustment factor, differences in biochemically-validated abstinence lacked significance, which is probably due to the low ratio of participants who attended biochemical validation 
and the lack of power resulting from not reaching the calculated sample size.

This outcome is similar to other studies. Kaper et al. ${ }^{23}$ reported a biochemically-validated abstinence rate of $5.5 \%$ in the intervention group and $2.8 \%$ in the control group ( $\mathrm{OR}=2.3$; 95\% CI: $1.2-4.1)$, and a selfreported abstinence of $7.8 \%$ and $5.5 \%,(\mathrm{OR}=1.5 ; 95 \%$ CI: $0.9-2.4$ ), respectively. Use of drug therapy was $10.8 \%$ in the financed group and $4.1 \%$ in the control (OR=2.9; 95\% CI: $1.8-4.7)$.

Selby et al. ${ }^{19}$ conducted a pragmatic study with similar results after 6 months, and the Cochrane Review relative risk was within the same range ${ }^{9}$. A study by Twardella et al. ${ }^{24}$ with a similar design by clusters found a continuous abstinence rate of $9 \%$ for a group provided with training and financing compared to $1 \%$ success in a group treated following usual clinical practice.

Financing pharmacological treatment can be an important factor to help vulnerable populations quit smoking $^{14-16}$. The higher the income, the greater the probability to cease smoking and the lower the tobacco consumption prevalence ${ }^{25}$. In this study, patients with a higher income level in both arms were more successful in quitting. However, in the intervention group, differences in drug use and abstinence rates were smaller between subjects with high- and lowincome levels, which indicate a tendency to balance pharmacological treatment use as a result of funding it (Table 3). High income level was considered to be greater than $€ 26000$ /year, the equivalent of more than 3 times the minimum interprofessional salary in the study period. The number of attempts to quit is considered a criterion of dependence: the greater the number of attempts, the greater the nicotine addiction. According to some studies ${ }^{23}$, smokers who have ever used drug therapy have more possibilities to re-use it if subsidized. In our study, smokers that had previously used drug therapy, used it more frequently, and also had greater chance to quit smoking (Table 4).

A study ${ }^{26}$ in the Netherlands reported the realworld experience of financing drug therapy in 2011 and compared the results with those from a $5 \%$ increase in tobacco prices at that time. Treatment funding yielded better health outcomes, although at a higher cost, but none of the mentioned strategies reduced the gap between social groups.
In most studies on this topic, NRT and Bupropion have been used. The latest also include Varenicline. All are considered first-line therapies in smoking cessation $^{1,2}$. According to the latest reviews Varenicline is more effective than Bupropion and single-form NRT but not of the combination $\mathrm{NRT}^{2,27}$. In this trial, all drugs have shown their effectiveness in stopping smoking. The use of NRT and Bupropion doubles the chances of quitting smoking and Varenicline triples them. They are figures similar to those found in the literature ${ }^{1}$. Each one of the three drugs was more used when the patient did not have to pay for it. Therefore, NRT, Bupropion and Varenicline would be candidates to be subsidized. In Spain, the main experience of financing treatment took place in the Autonomous Community of Navarra, between 2003 and 2012. After 5 years, since December 2017 , it is also subsidized in primary healthcare centers (HCCs), in the context of support and follow-up. In Madrid, a pilot funding experience was made in certain patients with chronic conditions for a few months in 2011. Treatments for other chronic conditions such as hypertension, diabetes, COPD, and alcohol abuse, have always been subsidized.

\section{Limitations and strengths}

There are some limitations to this study. The funding requested for the conduct of the study was estimated considering that $15-20 \%$ of smokers would make an attempt to quit but the rate was much higher in both groups, likely due to the real offer to actually quit smoking $^{28}$, together with a possible Hawthorne effect. Thus, the budget assigned to the project for funding pharmacological treatment ran out before completing the required sample size, since up to $58 \%$ of participants in the intervention group used pharmacological treatment. At the same time, the control group recruited less participants than expected, all of which resulted in a lack of power for some outcomes. This is probably related to the reallife impact of the intervention. Primary healthcare interventions are scarce ${ }^{3-8}$. The possibility of giving a treatment leads to an increased intervention by the practitioner, so many participants decided to make an attempt. In contrast, in the control group, recruitment was slower in the same period since interventions are rarer.

It is not to be expected that financing a drug will increase its efficacy, but that the number of attempts 
to quit smoking and the use of pharmacological support will be increased. Professionals attract more patients because they offer more financed treatment and patients decide to make an attempt as they know that treatment will be funded. The main reason for the difference in the distribution of the stages of change is most likely the treatment offer itself, which is the subject of the study, although selection bias cannot be discarded. This is why the multilevel analysis was not adjusted for the stages of change.

The calculation of the number of patients who would attempt to stop smoking was done according to the theoretical framework of the stages of change. Some authors suggest a different theoretical framework, called the 'Catastrophic theory'29, which considers motivation as a dynamic, fluctuating process where diverse stimuli can trigger attempts to quit. Even small triggers can lead to sudden 'catastrophic' changes. One of those stimuli that could trigger quit attempts could be the immediate offer of a funded treatment. In a clinical trial by Jardin et al. ${ }^{30}$, both motivated and unmotivated patients were given free NRT and referred to a telephone help-line for cessation, and similar abstinence rates were observed. Funding the treatment can be one trigger stimulus for less motivated smokers to attempt cessation. This may explain differences between groups across the different stages of the change process, and consequently in the number of quit attempts.

As is the case for studies by clusters, another possible limitation is the selection and attrition biases. The control arm recruited fewer patients, possibly due to the lack of involvement of health professionals not assigned to the intervention arm, and a higher number of centers in the control arm did not recruit any patients. Another bias can be the temporariness of the funding assigned to the project, of which health professionals were aware of and which may have influenced their decision to recruit more patients willing to quit smoking for the intervention group ${ }^{28}$. Identification of patients prior to randomization or blinding of professionals in charge or recruitment was not possible.

Another limitation is the irregular distribution of HCCs (cluster) in the two arms. The number of professionals in the control group (doctors and nurses) was much lower than in the intervention group (Figure 1), which may have influenced the lower uptake of patients in the control group. Despite this, the average uptake per center was not much lower in the control HCGs.

Among the strengths of this study is its pragmatic $\operatorname{design}^{31}$ for assessing the effect of treatment funding under real-life conditions. Recruitment, training of health professionals ${ }^{21}$, information and assistance for patients, and characteristics of healthcare centers and professionals were identical in both groups. Criteria for inclusion, flexibility to apply the intervention, comparison with usual practice, absence of formal, controlled follow-up visit, and the intention-to-treat analysis were also part of our pragmatic design. Smokers were treated by their assigned health professionals at usual consultations, without further limitations. Situations where pharmacological treatment is not indicated was the only exclusion criterion ${ }^{1}$. We consider that these results can be applied to real-world primary care consultations in the Spanish setting. Drug financing has not been modified in our environment since the trial was conducted.

An intervention on smoking dependence does not consist of a mere pharmacological prescription. Treatment mainly consists of behavioral counselling. However, use of drug therapy is an important facilitator, especially in the case of underprivileged patients, as is the case for the highly-dependent or those from a low socioeconomic level. Hence, funding this treatment in a manner similar to other treatments already financed by the public system is a key factor.

\section{CONCLUSIONS}

Financing pharmacological treatment of smoking addiction by the public health system increases abstinence rates and offers the opportunity to improve interventions for tobacco consumption in primary care, with increased number of attempts to quit and use of therapeutic drugs.

\section{REFERENCES}

1. US Department of Health and Human Services. Treating Tobacco Use and Dependence: 2008 Update. Rockville, MD: US Department of Health and Human Services; 2008. http://www.ncbi.nlm.nih.gov/books/NBK63952/. Accessed September 28, 2012.

2. Cahill K, Stevens S, Perera R, Lancaster T. Pharmacological interventions for smoking cessation: an overview and network meta-analysis. Cochrane Database Syst Rev. 2013;(5):CD009329. doi:10.1002/14651858.CD009329.pub2 
3. Edwards SA, Bondy SJ, Callaghan RC, Mann RE. Prevalence of unassisted quit attempts in population-based studies: a systematic review of the literature. Addict Behav. 2014;39(3):512-519. doi:10.1016/j.addbeh.2013.10.036

4. Bartsch A-L, Härter M, Niedrich J, Brütt AL, Buchholz A. A Systematic Literature Review of Self-Reported Smoking Cessation Counseling by Primary Care Physicians. PloS One. 2016;11(12):e0168482. doi:10.1371/journal.pone.0168482

5. Kruger J, O'Halloran A, Rosenthal AC, Babb SD, Fiore MC. Receipt of evidence-based brief cessation interventions by health professionals and use of cessation assisted treatments among current adult cigarette-only smokers: National Adult Tobacco Survey, 2009-2010. BMC Public Health. 2016;16(1):141. doi:10.1186/s12889-016-2798-2

6. Bernstein SL, Yu S, Post LA, Dziura J, Rigotti NA. Undertreatment of tobacco use relative to other chronic conditions. Am J Public Health. 2013;103(8):e59-65. doi:10.2105/AJPH.2012.301112

7. Jarlenski M, Hyon Baik S, Zhang Y. Trends in Use of Medications for Smoking Cessation in Medicare, 2007-2012. Am J Prev Med. 2016;51(3):301-308. doi:10.1016/j.amepre.2016.02.018

8. Gross B, Brose L, Schumann A, et al. Reasons for not using smoking cessation aids. BMC Public Health. 2008;8:129. doi:10.1186/1471-2458-8-129

9. van den Brand FA, Nagelhout GE, Reda AA, et al. Healthcare financing systems for increasing the use of tobacco dependence treatment. Cochrane Database Syst Rev. 2017;9:CD004305. doi:10.1002/14651858.CD004305.pub5

10. Verbiest MEA, Chavannes NH, Crone MR, et al. An increase in primary care prescriptions of stop-smoking medication as a result of health insurance coverage in the Netherlands: population based study. Addiction. 2013;108(12):2183-2192. doi:10.1111/add.12289

11. Willemsen MC, Segaar D, van Schayck OCP. Population impact of reimbursement for smoking cessation: a natural experiment in The Netherlands. Addict Abingdon Engl. 2013;108(3):602-604. doi:10.1111/j.1360-0443.2012.04089.x

12. Land T, Warner D, Paskowsky M, et al. Medicaid coverage for tobacco dependence treatments in Massachusetts and associated decreases in smoking prevalence. PloS One. 2010;5(3):e9770. doi:10.1371/journal.pone.0009770

13. World Health Organization. WHO Report on the global tobacco epidemic, 2008: the MPOWER package. 2008. https://www.who.int/tobacco/mpower/2008/en/. Accessed April 27, 2019.

14. Ferguson J, Docherty G, Bauld L, et al. Effect of offering different levels of support and free nicotine replacement therapy via an English national telephone quitline: randomised controlled trial. BMJ. 2012;344:e1696. doi:10.1136/bmj.e1696

15. Sheffer CE, Stitzer M, Landes R, Brackman SL, Munn T, Moore P. Socioeconomic disparities in community-based treatment of tobacco dependence. Am J Public Health. 2012;102(3):e8-e16. doi:10.2105/AJPH.2011.300519

16. Hiscock R, Dobbie F, Bauld L. Smoking Cessation and Socioeconomic Status: An Update of Existing Evidence from a National Evaluation of English Stop Smoking Services. BioMed Res Int. 2015;2015:274056. doi:10.1155/2015/274056

17. Land T, Rigotti NA, Levy DE, et al. A longitudinal study of medicaid coverage for tobacco dependence treatments in Massachusetts and associated decreases in hospitalizations for cardiovascular disease. PLoS Med. 2010;7(12):e1000375. doi:10.1371/journal.pmed.1000375

18. Dey P, Foy R, Woodman M, Fullard B, Gibbs A. Should smoking cessation cost a packet? A pilot randomized controlled trial of the cost-effectiveness of distributing nicotine therapy free of charge. Br J Gen Pract. 1999;49(439):127. PMID:10326267.

19. Selby P, Brosky G, Oh P, Raymond V, Arteaga C, Ranger S. A pragmatic, randomized, controlled study evaluating the impact of access to smoking cessation pharmacotherapy coverage on the proportion of successful quitters in a Canadian population of smokers motivated to quit (ACCESSATION). BMC Public Health. 2014;14(1):433. doi:10.1186/1471-2458-14-433

20. Parrott S, Godfrey C, Raw M, West R, McNeill A. Guidance for commissioners on the cost effectiveness of smoking cessation interventions. Health Educational Authority. Thorax. 1998;53 Suppl 5 Pt 2:S1-38. PMID:10226676.

21. Olano-Espinosa E, Matilla-Pardo B, Minue C, Anton E, Gomez-Gascon T, Ayesta FJ. Effectiveness of a Health Professional Training Program for Treatment of Tobacco Addiction. Nicotine Tob Res. 2013;15(10):1682-1689. doi:10.1093/ntr/ntt040

22. West R, Hajek P, Stead L, Stapleton J. Outcome criteria in smoking cessation trials: proposal for a common standard. Addict Abingdon Engl. 2005;100(3):299-303. doi:10.1111/j.1360-0443.2004.00995.x

23. Kaper J, Wagena EJ, Willemsen MC, van Schayck CP. Reimbursement for smoking cessation treatment may double the abstinence rate: results of a randomized trial. Addict Abingdon Engl. 2005;100(7):1012-1020. doi:10.1111/j.1360-0443.2005.01097.x

24. Twardella D, Brenner H. Effects of practitioner education, practitioner payment and reimbursement of patients' drug costs on smoking cessation in primary care: a cluster randomised trial. Tob Control. 2007;16(1):15-21. doi:10.1136/tc.2006.016253

25. Du J, Leigh JP. Effects of wages on smoking decisions of current and past smokers. Ann Epidemiol. 2015;25(8):575582.e1. doi:10.1016/j.annepidem.2015.03.016

26. Over EAB, Feenstra TL, Hoogenveen RT, Droomers M, Uiters E, van Gelder BM. Tobacco control policies specified according to socioeconomic status: health disparities and cost-effectiveness. Nicotine Tob Res. 2014;16(6):725-732. doi:10.1093/ntr/ntt218

27. Cahill K, Lindson-Hawley N, Thomas KH, Fanshawe TR, 
Lancaster T. Nicotine receptor partial agonists for smoking cessation. Cochrane Database Syst Rev. 2016;(5):CD006103. doi:10.1002/14651858.CD006103.pub7

28. Aveyard P, Begh R, Parsons A, West R. Brief opportunistic smoking cessation interventions: a systematic review and meta-analysis to compare advice to quit and offer of assistance: Brief interventions for smoking cessation. Addiction. 2012;107(6):1066-1073. doi:10.1111/j.1360-0443.2011.03770.x

29. West R, Sohal T. 'Catastrophic' pathways to smoking cessation: findings from national survey. BMJ. 2006;332(7539):458460. doi:10.1136/bmj.38723.573866.AE

30. Jardin BF, Cropsey KL, Wahlquist AE, et al. Evaluating the effect of access to free medication to quit smoking: a clinical trial testing the role of motivation. Nicotine Tob Res Off J Soc Res Nicotine Tob. 2014;16(7):992-999. doi:10.1093/ntr/ntu025

31. Thorpe KE, Zwarenstein M, Oxman AD, et al. A pragmatic-explanatory continuum indicator summary (PRECIS): a tool to help trial designers. J Clin Epidemiol. 2009;62(5):464-475. doi:10.1016/j.jclinepi.2008.12.011

\section{ACKNOWLEDGEMENTS}

We thank each of the many personnel, of the 24 participating health centers, whose names are listed in the Supplementary file Acknowledgements.

\section{CONFLICTS OF INTEREST}

The authors declare that they have no competing interests, financial or otherwise, related to the current work. C. Minué-Lorenzo reports grants from Fondo de Investigaciones Sanitarias (FIS) del Instituto de Salud Carlos III (ISCIII), European Regional Development Fund (ERDF), grants from Fundación para la Investigación e Innovación Biosanitaria en Atención Primaria (FIIBAP), during the conduct of the study. The rest of the authors have also completed and submitted an ICMJE form for disclosure of potential conflicts of interest.

\section{FUNDING}

This trial was funded by the Fondo de Investigaciones Sanitarias (FIS) del Instituto de Salud Carlos III (ISCIII), the European Regional Development Fund (ERDF) under registration number 07528, as well as the 2016 and 2017 calls for grants for translations and publishing by the Fundación para la Investigación e Innovación Biosanitaria en Atención Primaria (FIIBAP).

\section{AUTHORS' CONTRIBUTIONS}

The idea for the study was conceived by C.M.L. and E.O.E.; J.M.V.S., F.C.G., J.A.G.G. and M.R.P. also participated in the design of the study. All coordinated the field work, together with M.I.G.C. and F.J.M.S; I.C.G. carried out the data analysis and interpretation, and wrote the first draft of the paper jointly with C.M.L. and E.O.E. The other authors and E.S.S. contributed ideas, interpreted the findings, critically reviewed the draft and approved the final version. 